\title{
Clinical outcome of patients treated with spinal cord stimulation for therapeutically refractory angina pectoris
} I A M TenVaarwerk, G A J Jessurun, M J L DeJongste, C Andersen, C Mannheimer,
T Eliasson, W Tadema, M J Staal, for the Working Group on Neurocardiology
Angina pectoris, the main clinical symptom related to ischaemic heart disease, is associated with an impaired residual coronary flow reserve. The coronary flow reserve determines the ischaemic threshold. In a patient who has exercise induced angina, the product of heart rate and systolic blood pressure increases, which leads to an imbalance between coronary flow reserve and myocardial oxygen consumption. ${ }^{1}$

To date, the majority of patients suffering from ischaemic heart disease can be adequately treated by anti-ischaemic drugs and revascularisation procedures. Anti-ischaemic and antianginal drugs, such as $\beta$ blocking agents, calcium channel blockers, and long acting nitrates, reduce the oxygen demand or increase the myocardial oxygen supply by vasodilatation. Revascularisation procedures, such as percutaneous transluminal coronary angioplasty (PTCA) or coronary artery bypass grafting (CABG), increase the oxygen supply to the ischaemic myocardium.

Improved drugs and surgical treatment have increased the life expectancy of patients suffering from ischaemic heart disease. However, there are some patients who remain severely disabled by angina pectoris. These patients with intractable angina are no longer candidates for revascularisation procedures. Moreover, despite the maximum tolerated antiischaemic drug treatment, the patients suffer from chest discomfort during minimal exercise or even at rest. ${ }^{2-4}$ For these patients any treatment that improves the quality of life without adversely affecting their prognosis should be considered. Neuromodulation through the application of an electrical current to the spinal cord-spinal cord stimulationmay be one such treatment. The implantation procedure of a spinal cord stimulator is described in detail elsewhere. ${ }^{45}$

The efficacy of spinal cord stimulation depends on the accurate placement of the stimulating electrode in the dorsal epidural space. The paraesthesia induced by the stimulator should correspond to the area where the patients experience anginal pain. When the tip of the electrode is correctly positioned, usually at the C7-T1 level, the lead is anchored and connected to a pulse generator, generally placed in a subcutaneous pocket in the upper abdominal wall. The stimulator can be activated (or deactivated) by the patient, either through application of a magnet or by making use of the patient programmer. 
Table 1 Baseline characteristics for survivors and non-survivors

\begin{tabular}{|c|c|c|c|c|}
\hline & Entire group $(n=517)$ & Died $(n=103)$ & Survived $(n=413)$ & $p$ Value \\
\hline Median (range) follow up (months) & 23 (0 to 128$)$ & $19(0$ to 122$)$ & $23(0$ to 128$)$ & 0.18 \\
\hline \multicolumn{5}{|l|}{ Demographics } \\
\hline $\operatorname{Sex}(M / F)$ & $367 / 150$ & $83 / 20$ & $281 / 132$ & 0.01 \\
\hline Age (years) (mean (SD)) & $63.9(10.1)$ & $65.7(10.6)$ & $63.5(9.9)$ & 0.07 \\
\hline \multicolumn{5}{|l|}{ Clinical presentation } \\
\hline Duration of angina (years) (mean (SD)) & $8.1(6.3)$ & $8.1(6.1)$ & $8.0(6.4)$ & 0.90 \\
\hline NYHA class (mean (SD)) & $3.5(0.7)$ & $3.5(0.8)$ & $3.3(0.6)$ & 0.45 \\
\hline \multicolumn{5}{|l|}{ Cardiovascular status } \\
\hline $\mathrm{LVEF} \leqslant 40 \%$ & $24 \%$ & $44 \%$ & $19 \%$ & $<0.01$ \\
\hline Previous MI & $66 \%$ & $78 \%$ & $63 \%$ & $<0.01$ \\
\hline Three vessel disease & $68 \%$ & $82 \%$ & $64 \%$ & $<0.01$ \\
\hline PTCA & $17 \%$ & $8 \%$ & $18 \%$ & 0.02 \\
\hline CABG & $58 \%$ & $60 \%$ & $57 \%$ & 0.64 \\
\hline \multicolumn{5}{|l|}{ Risk factors } \\
\hline Family history of CAD & $61 \%$ & $66 \%$ & $59 \%$ & 0.50 \\
\hline Hypertension & $39 \%$ & $45 \%$ & $37 \%$ & 0.16 \\
\hline Hypercholesterolaemia & $28 \%$ & $26 \%$ & $29 \%$ & 0.60 \\
\hline Smoking & $21 \%$ & $24 \%$ & $21 \%$ & 0.58 \\
\hline IDDM & $14 \%$ & $20 \%$ & $13 \%$ & 0.05 \\
\hline \multicolumn{5}{|l|}{ Drug treatment } \\
\hline Calcium channel blockers & $73 \%$ & $76 \%$ & $73 \%$ & 0.46 \\
\hline$\beta$ Blockers & $66 \%$ & $56 \%$ & $69 \%$ & 0.02 \\
\hline ACE inhibitors & $25 \%$ & $29 \%$ & $23 \%$ & 0.30 \\
\hline Short acting nitrates & $95 \%$ & $92 \%$ & $95 \%$ & 0.23 \\
\hline Long acting nitrates & $79 \%$ & $79 \%$ & $79 \%$ & 1.00 \\
\hline
\end{tabular}

p Values were obtained by univariate analysis: two tailed Fisher's exact test for discrete and Student's $t$ test or Mann Whitney U test for continous variables.

ACE, angiotensin converting enzyme; CABG, coronary artery bypass graft surgery; CAD, coronary artery disease; IDDM, insulin dependent diabetes mellitus; LVEF, left ventricular ejection fraction; MI, myocardial infarction; NYHA, New York Heart Association functional class; PTCA, percutaneous transluminal coronary angioplasty.

The first report on the antianginal effect of spinal cord stimulation in patients with intractable angina was published in 1987. Murphy and Giles showed a reduction in both the frequency and severity of anginal attacks, with a concomitant reduction in sublingual intake of nitrate tablets. ${ }^{6}$ Although these findings were promising, many physicians were sceptical. However, during the last decade numerous clinicians have advocated spinal cord stimulation as an effective additional approach for patients disabled by chronic anginal pain. ${ }^{4-11}$ To date, in selected patients spinal cord stimulation may be considered as an alternative to bypass surgery. ${ }^{12}$ However, further studies are needed to confirm the safety of spinal cord stimulation in patients suffering from end stage coronary artery disease.

Recent investigations have shown that the antianginal effect of neurostimulation is related to an anti-ischaemic effect. Ambulatory ECG recordings and exercise stress tests showed that ST segment depression, an indicator of the presence of myocardial ischaemia, was reduced during spinal cord stimulation. ${ }^{4589}$ de Landsheere et al demonstrated a reduction in angina and an increased time to the onset of ischaemia. ${ }^{13}$ However, myocardial perfusion was not increased during maximum exercise. In contrast to these previous findings, Hautvast et al reported that neuromodulation improved myocardial perfusion in ischaemic regions, with a concomitant alteration of the coronary flow reserve as assessed by positron emission tomography. ${ }^{14}$ The difference in outcome between the two studies may be explained by the protocol and the equipment used. Chauhan et al produced an increase in coronary flow velocity by neuromodulation. ${ }^{15}$ The increase in myocardial blood flow during neuromodulation suggests that electrical neurostimulation relieves anginal pain by its anti-ischaemic properties. This method of treatment may thus be considered safe. A beneficial effect of spinal cord stimulation has been reported in studies on its long term clinical application as adjuvant treatment in patients with refractory angina. ${ }^{8} 16$ These studies are limited by the open observational design and the small number of patients. Moreover, there are no data on mortality in a large population of patients treated by spinal cord stimulation for refractory angina. For this reason, a multicentre study was conducted, with data collection by questionnaire. The primary objective of this study was to evaluate clinical characteristics, overall mortality, and cardiac mortality in patients treated with spinal cord stimulation for angina pectoris. The secondary aim was to analyse morbidity aspects by comparing medical history at baseline (before spinal cord stimulator implantation) with follow up data.

\section{Methods}

A standardised questionnaire was developed to obtain data on survival and medical history in patients treated with spinal cord stimulation for angina. Physicians worldwide who were known to implant spinal cord stimulation devices for angina were asked to fill in the questionnaire on a voluntary basis (see list of participating centres at the end). The evaluation form contained 35 items divided into seven paragraphs. These had to be completed for each patient. The seven paragraphs refer to:

- general information (sex and age)

- spinal cord stimulator implantation date and efficacy of the treatment (is the treatment still effective? Has the patient died? If so, what was the cause of death, according to ICD-9 codes 410-414?)

- previous medical history (duration of anginal complaints, number of previous myocardial infarcts and revascularisation procedures, left ventricular ejection fraction) 
Table 2 Survival analysis

\begin{tabular}{lll}
\hline & $p$ Value $^{*}$ & Risk ratio \\
\hline $\begin{array}{lll}\text { Demographics } \\
\text { Age } \geqslant 71 \text { years }\end{array}$ & $<0.01$ & 2.15 \\
Sex $(\mathrm{M} / \mathrm{F})$ & 0.01 & 1.90 \\
Cardiovascular status & & \\
LVEF $\leqslant 40 \%$ & $<0.01$ & 3.49 \\
Previous MI & $<0.01$ & 2.43 \\
Three vessel disease & $<0.01$ & 2.34 \\
PTCA & 0.05 & 0.46 \\
Risk factors & & \\
IDDM & 0.01 & 1.85 \\
Drug treatment & & \\
$\beta$ Blockers & $<0.01$ & 0.58 \\
ACE inhibitors & $<0.01$ & 1.32
\end{tabular}

^Wald $\chi^{2}$ test.

ACE, angiotensin converting enzyme; IDDM, insulin dependent diabetes mellitus; LVEF, left ventricular ejection fraction; PTCA, percutaneous transluminal coronary angioplasty.

- the use of antianginal drugs ( $\beta$ blockers, calcium channel blockers, angiotensin converting enzyme (ACE) inhibitors, nitrates)

- risk factors for coronary artery disease (family history of coronary artery disease, smoking, hypercholesterolaemia, diabetes, hypertension)

- the method of evaluating the efficacy of spinal cord stimulation (ambulatory ECG monitoring, exercise testing, questionnaires, diaries, and so on) and the morbidity during follow up

- the name and signature of the investigator. In relation to the second item, the cause of death was scored as either a cardiac death or a death due to other causes. The annual mortality was determined from the date of the implantation of the spinal cord stimulation system until the date of explantation or death. Morbidity (item 6) was evaluated by recording complications, myocardial infarcts, hospital admissions, and alterations in the New York Heart Association (NYHA) functional classification.

The clinical characteristics at the implantation date were analysed and compared between survivors and non-survivors. To evaluate the potential influence of neurostimulation on

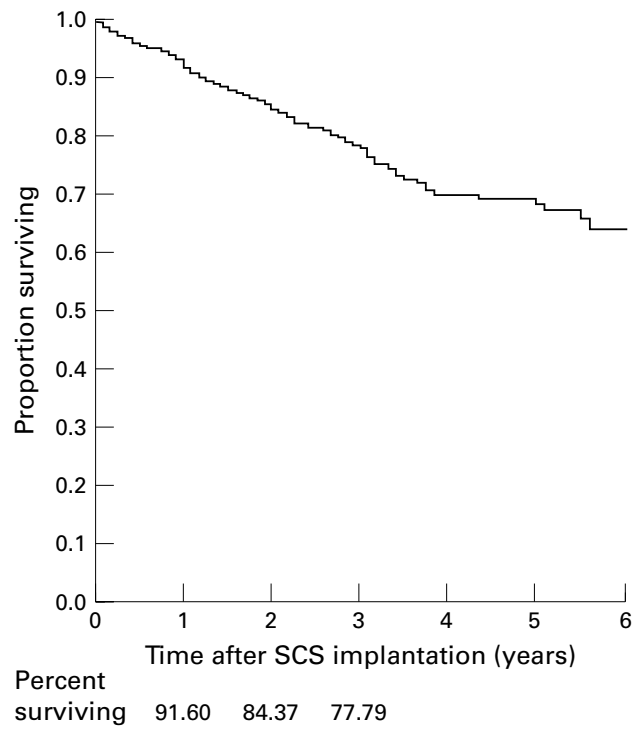

surviving $91.60 \quad 84.37 \quad 77.79$

Figure 1 Kaplan-Meier survival curve for entire group of patients. SCS, spinal cord stimulation.
Table 3 Mean left ventricular ejection fractions ( $L V E F$ ) at baseline of survivors and non-survivors

\begin{tabular}{llll}
\hline Year & $\begin{array}{l}\text { Entire group } \\
(n=397)\end{array}$ & $\begin{array}{l}L V E F \leqslant 40 \% \\
(n=94)\end{array}$ & $\begin{array}{l}L V E F>40 \% \\
(n=303)\end{array}$ \\
\hline 1 & $7.6 \%$ & $15 \%$ & $4 \%$ \\
2 & $7.0 \%$ & $16 \%$ & $4 \%$ \\
3 & $7.0 \%$ & $14 \%$ & $5 \%$ \\
\hline
\end{tabular}

morbidity and mortality in patients with therapeutically refractory angina pectoris, the characteristics at follow up and baseline were compared.

STATISTICAL ANALYSIS

Discrete variables are expressed as the percentage of the total within each subgroup (deceased or surviving patients) and the $\chi^{2}$ test or Fisher's exact test was used to test for differences between subgroups. Continuous variables that were approximately normally distributed are expressed as the mean (SD). If the distribution pattern of variables was skewed, the median (minimum to maximum) is given. Depending on the distribution of variables either the parametric Student $t$ test or the non-parametric Mann Whitney U test was performed. All tests were two sided and a $\mathrm{p}$ value of $<0.05$ was considered statistically significant.

To reveal which factors determine mortality and survival time, survival data were analysed. First, each baseline variable was analysed separately and the estimated risk ratio and accompanying $p$ value of the Wald $\chi^{2}$ test was computed using a proportional hazards model. Linearity of the continuous variables (for example, age) with respect to the response variable was assessed by determining the quartiles of their distribution. Thereafter, risk ratios for each quartile were calculated. In case of a

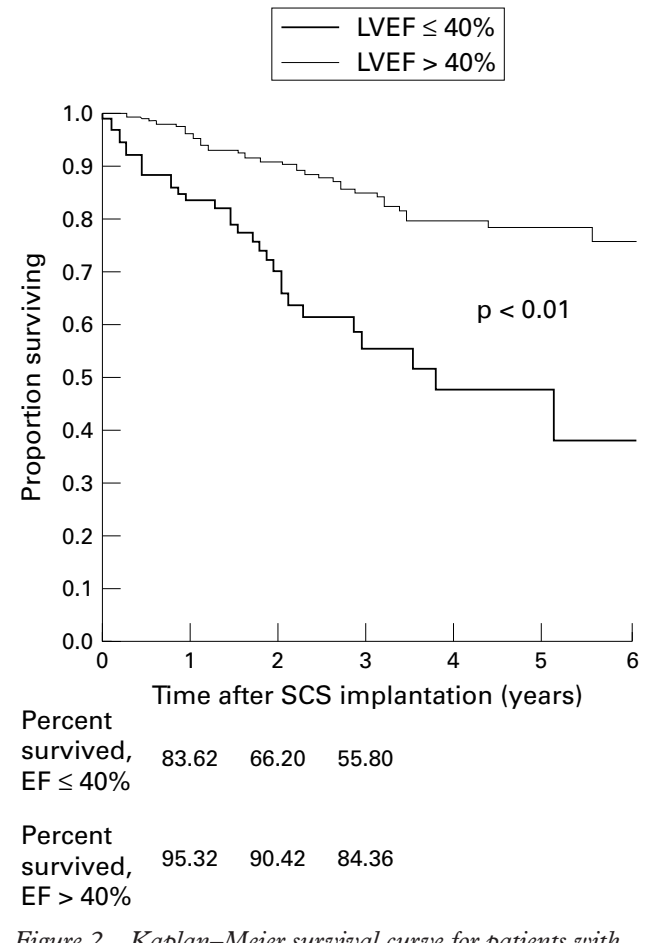

Figure 2 Kaplan-Meier survival curve for patients with a left ventricular ejection fraction of $\leqslant 40 \%$ and $>40 \%$ (see text for details). SCS, spinal cord stimulation. 


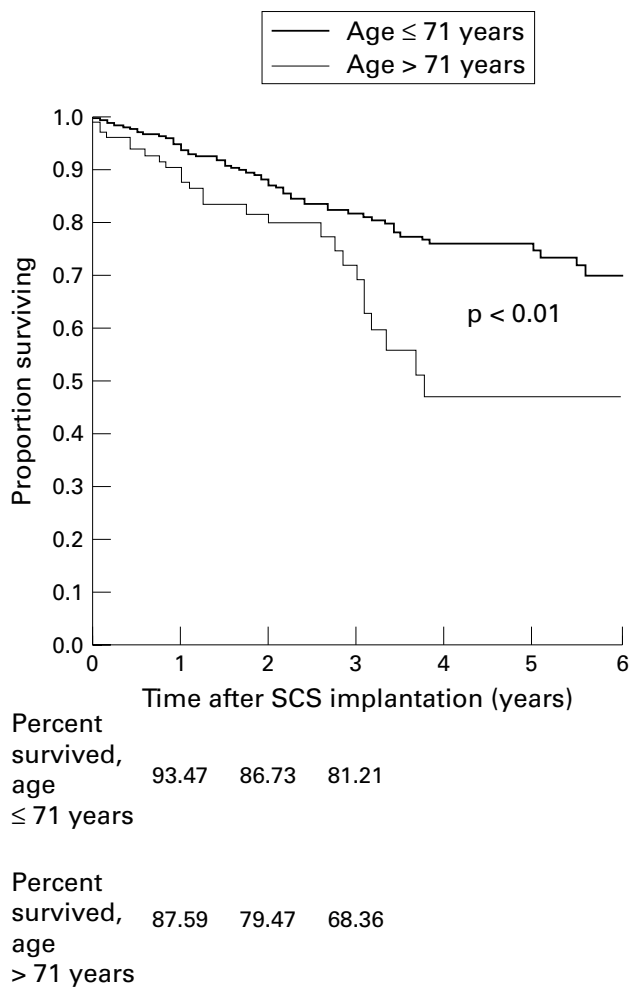

Figure 3 Kaplan-Meier survival curves for patients with age $\leqslant 71$ years and $>71$ years (see text for details). SCS, spinal cord stimulation.

Table 4 New York Heart Association (NYHA) score at baseline and during follow up for angina pectoris in the entire group

\begin{tabular}{|c|c|c|c|}
\hline \multicolumn{2}{|c|}{ NYHA class at baseline } & \multicolumn{2}{|c|}{ NYHA class at follow up } \\
\hline I & $2 \%$ & I & $24 \%$ \\
\hline II & $5 \%$ & II & $48 \%$ \\
\hline III & $42 \%$ & III & $21 \%$ \\
\hline IV & $51 \%$ & IV & $7 \%$ \\
\hline $\begin{array}{c}\text { Mean NYHA } \\
\text { score } 3.5\end{array}$ & $100 \%$ & $\begin{array}{c}\text { Mean NYHA } \\
\text { score } 2.1^{\star}\end{array}$ & $100 \%$ \\
\hline
\end{tabular}

linear trend in the estimated risk ratios the variable was introduced into the model as continuous. If no linearity was demonstrated, the variable was further categorised by merging the quartiles with risk ratios similar in magnitude. Second, a Cox proportional hazards model was employed to assess the simultaneous effect of several independent variables on survival time. All variables with a $p$ value $<0.20$ in the univariate analysis were introduced into this multivariate model. A forward selection procedure was used for model selection. Possible interactions between variables were tested.

Data were analysed using SAS version 6.11 (SAS institute, Cary, North Carolina, USA).

\section{Results}

Evaluation forms were sent to 21 centres, which were expected to enrol about 700 patients. Fourteen centres returned their completed questionnaire forms. Between 1987 and 1997, 517 patients treated with spinal cord stimulation for intractable angina at these centres were recruited. One patient was lost to follow up. Median follow up was 23 (0 to 128) months for the entire group of patients, 23 (0 to 128 ) months for the survivors, and 19 (0 to 122) months for the deceased.

The NYHA classification, years of angina before neurostimulation, and mean follow up time after spinal cord stimulation at baseline were not different between survivors and nonsurvivors (table 1). In the deceased group, the number of male patients was larger $(p=0.01)$, coronary artery disease was more severe (there were more previous myocardial infarcts $(\mathrm{p}<0.01)$, three vessel disease was more often encountered $(p<0.01)$, and the subjects had more severely reduced left ventricular function $(p<0.01))$. Insulin dependent diabetes was the only important risk factor between the groups $(\mathrm{p}=0.05)$.

Multivariate analysis showed that age $>71$ years $(p<0.01)$, sex $(p=0.01)$, left ventricular ejection fraction $(\mathrm{p}<0.01)$, previous myocardial infarcts $(p<0.01)$, the presence of three vessel disease $(p<0.01)$, diabetes $(p=0.01)$, and the use of $\beta$ blocking drugs $(p<0.01)$ and ACE inhibitors $(p<0.01)$ were significantly correlated with mortality (table 2 ). In the multivariate regression analysis only the use of $\beta$ blockers, sex, age $>71$ years, and left ventricular ejection fraction were predictors of outcome.

Of the 516 patients evaluated, $103(20 \%)$ died in the period during which they were receiving spinal cord stimulation treatment (fig 1). The cause of death was recorded as cardiac in 52 of the 103 fatalities, as non-cardiac in 25, and as unknown in 26. In the first three years after the spinal cord implant, overall mortality ranged between $7 \%$ and $8 \%$ ( $7.6 \%$ at one year; $7.0 \%$ at two years; $7.0 \%$ at three years). Cardiac death was estimated to be 3.5-5\%/year in this group of patients. The ejection fraction was determined in 397 patients (table 3). During the three year follow up, the patients with left ventricular ejection fractions $\leqslant 40 \%$ had an annual mortality of $14 \%$ and $16 \%$; mortality in patients with a left ventricular ejection fraction of $>40 \%$ was $4 \%$ to $5 \%$ annually.

The survival curves for patients with ejection fractions both $\leqslant 40 \%$ and $>40 \%$ are given in fig 2 and for patients aged $>71$ years and $\leqslant 71$ years in fig 3 .

Table 5 Follow up duration and morbidity

\begin{tabular}{llllll}
\hline & $\begin{array}{l}\text { Entire group } \\
(n=516)\end{array}$ & $\begin{array}{l}\text { Deceased } \\
(n=103)\end{array}$ & $\begin{array}{l}\text { Survivors } \\
(n=413)\end{array}$ & $p$ Value* & Odds ratio $^{*}$ \\
\hline MI after SCS implant & 57 & $25(24 \%)$ & $32(8 \%)$ & $<0.01$ & 3.719 \\
Hospital admissions after SCS implant & 213 & $67(66 \%)$ & $146(37 \%)$ & $<0.01$ & 3.287 \\
Hospital admissions (median (range)) & $2(1$ to 34$)$ & $2(1$ to 17$)$ & $2(1$ to 34) & 0.44 & NA \\
\hline
\end{tabular}

$\star$ Wilcoxon test.

MI, myocardial infarction; NA, not assessed; SCS, spinal cord stimulation. 
The efficacy of the treatment was assessed by the NYHA classification before implantation (score 3.5) and at the latest follow up date (score 2.1) $(\mathrm{p}<0.01)$. Before spinal cord stimulation $93 \%$ of the patients were recorded as being in NYHA class III-IV; during spinal cord stimulation this number was reduced to $28 \%$ (table 4 ). Hospital admissions were more frequent in the deceased group $(66 \%)$ than in the survivors $(37 \%) \quad(\mathrm{p}<0.01$; table 5$)$. Finally, 24 of the 103 deceased patients $(25 \%)$ experienced an acute myocardial infarct during spinal cord stimulation compared with $32(8 \%)$ of the 411 survivors ( $p<0.05$; table 5$)$.

\section{Discussion}

The study group is characterised by end stage coronary artery disease, severely disabling angina not responsive to conventional treatment, and a moderately reduced left ventricular ejection fraction. ${ }^{23}$ The study patients may be considered as survivors because of their relatively good left ventricular function. Moreover, the characteristics of the patients were compatible with earlier results from Cameron et al, which showed that the recurrence of angina after bypass surgery does not affect survival. ${ }^{17}$ The failure of conventional management in these patients with refractory angina has led to the increased use of spinal cord stimulation. This type of treatment has had favourable results, such as a reduction in both frequency and severity of anginal attacks, a decrease in the intake of short acting nitrates, and an increase in exercise capacity and time to angina. ${ }^{4-10}$ The reported reduction in angina during spinal cord stimulation is compatible with the data in our study. We found an improvement in NYHA functional score when the value at baseline (mean 3.5) was compared with the value during spinal cord stimulation (mean 2.1) (table 4).

Although the symptomatic improvement will have a beneficial effect on the quality of life in these patients, this does not necessarily imply an improvement in prognosis. Although spinal cord stimulation reduces myocardial ischaemia, ${ }^{458914}$ the treatment may mask the anginal symptoms. As the deceased patients had more myocardial infarcts $(24 \% v 8 \%)$ and hospital admissions ( $66 \%$ v $37 \%$ ) than the survivors (table 5), this may imply that the patients were aware of the different type of angina felt during an evolving myocardial infarct. Furthermore, the difference in angina perception may be explained by the severity of the disease (table 1).

The results from earlier studies do not suggest an increase in mortality during spinal cord stimulation. ${ }^{81116}$ In an observational study, Sanderson et al reported three deaths in a group of 23 patients over a mean period of 45 months. ${ }^{8}$ These investigators emphasised that this did not constitute an excess of sudden deaths in this group of patients. They found no evidence that spinal cord stimulation either induced a complete suppression of pain or masked the anginal pain during an acute myocardial infarct. In another study, Jessurun et al reported nine deaths (two non-cardiac) in a group of 57 patients treated by spinal cord stimulation for angina during 2042 patientmonths of follow up (range 1 to 72 )..$^{16}$

It is known that the angina occurring in patients who experience an acute myocardial infarct is not concealed by spinal cord stimulation. ${ }^{116}$ All three observational studies confirm that fears over the abolition of the anginal warning signal are unfounded; they therefore refute one of the main concerns about the safety of spinal cord stimulation treatment.

At baseline in the study group, the average time during which the patients had suffered from angina was 8.1 (6.3) years. The majority had three vessel disease, previous myocardial infarction, and the need for a revascularisation procedure (table 1). The differences in baseline characteristics between the surviving and deceased patients were related to insulin dependent diabetes, the severity of the disease, and left ventricular function, and inversely to the use of $\beta$ blockers. Multivariate analysis showed that an age $>71$ years, male sex, left ventricular ejection fraction, number of myocardial infarcts, presence of three vessel disease, diabetes, and the use of $\beta$ blocking drugs or ACE inhibitors were significantly correlated with mortality (table 2). In the multivariate regression analysis only the use of $\beta$ blockers, sex, age $>71$ years, and left ventricular ejection fraction were predictors of outcome.

This study shows that the overall mortality of patients with angina pectoris treated with spinal cord stimulation ranges between $7 \%$ and $8 \%$ in the first three years after the implantation of the spinal cord stimulator. A quarter of the study patients died of an unknown cause and three quarters died of a cardiac cause. This implies that the cardiac mortality rate in this patient group is around $3.5-5 \%$. Since no data are available on the cardiac death rate in patients with severe angina unresponsive to drug treatment and revascularisation procedures, the results in our study group were compared with data from a search of published reports on patients with stable angina. ${ }^{17-23}$ However, in a recent randomised investigation with a comparable study population, mortality was not adversely influenced by neurostimulation when compared with CABG. ${ }^{12}$ Moreover, $24 \%$ of symptom-free patients after CABG had reversible myocardial ischaemia with a $9 \%$ risk of subsequent death. ${ }^{23}$ That study group is also comparable with our present patient population, in which there were objective signs of ischaemia before treatment with spinal cord stimulation.

In our study the major prognostic factors for death were the left ventricular ejection fraction and the severity of coronary artery disease. This is in agreement with the outcomes of the coronary artery surgery study (CASS) registry $^{17} 2122$ and the Framingham study. ${ }^{23}$

The CASS data showed that the four year mortality for medically treated patients with stable angina was $16 \%$ with two vessel disease and $32 \%$ with three vessel disease. For patients with three vessel disease and a left ventricular ejection score of $\geqslant 10$, the four year mortality 
was $35 \%$. A left ventricular ejection score $<10$ had a mortality of $15 \%$. The mortality after two to three years of initial medical treatment was estimated to be about $20-30 \%$ by stratification of specific group characteristics (that is, the number of vessels diseased, the left ventricular ejection fraction, and the severity of recurrent angina after revascularisation). Our results suggest that the mortality in our own study group $(78 \%$ overall survival after three years) does not exceed the mortality in more or less comparable groups of patients.

\section{LIMITATIONS OF THE STUDY}

This was a retrospective study. The study population may be considered to be survivors because they had a mean history of symptomatic coronary artery disease of eight years, severe multivessel coronary artery disease, and reasonable left ventricular function. There is no control group for comparison of survival data. On the other hand, in a prospective study with an estimated annual mortality of $7 \%$, a power of $80 \%$, and an $\alpha$ of $5 \%$, at least 2200 patients in each group would need to be enrolled to demonstrate equivalence $( \pm 1 \%)$ in outcome after a three year follow up. In addition, since the patient is aware of paraesthesiae and physicians may notice the stimulation artefacts on the ECG, a blinded or crossover control design is not possible.

The indications for spinal cord stimulator implantation for intractable angina may differ among the different centres. Although data on the duration of the effectiveness of spinal cord stimulation were obtained, detailed information on stimulation time and stimulation parameters is as yet unavailable. Therefore, it is not possible to define the efficacy of the treatment precisely. Any lack of efficacy might be stimulator related (depletion of the spinal cord stimulator battery, lead fracture or migration, and so on) or caused by inadequate adjustment of the stimulation parameters.

\section{CONCLUSIONS}

All cause mortality in patients with spinal cord stimulation therapy for angina pectoris is estimated to be around $7-8 \%$ and cardiac mortality $3.5-5 \%$. Overall mortality was about $20 \%$ (103 of 516 patients died, including one patient who was lost to follow up). The surviving group had fewer hospital admissions and myocardial infarcts. The left ventricular ejection fraction and the severity of the coronary artery disease were predictive of the clinical outcome, which was comparable with previous studies. We conclude that the characteristics of the patients in our study, who were prone to die from severe coronary disease, did not differ from those of the patients in the CASS studies who were medically treated for angina. Therefore spinal cord stimulation used as an adjuvant treatment in patients with refractory angina appears not to have an adverse effect on either mortality or morbidity.

In this study spinal cord stimulation improved the functional NYHA classification. Spinal cord stimulation increases the quality of life, has anti-ischaemic properties, and is a safe adjuvant treatment in patients with refractory angina. Its future success depends on its general acceptance by all physicians involved in the treatment of patients with intractable angina.

We gratefully acknowledge the support of Medtronic Inc, Minneapolis, Minnesota, USA

List of participating centres

Dr R Goucke, Sir Charles Gairdner Hospital, Verdun SL Nedlands, Perth, Western Australia; Dr D Savard, Notre Dame, 1560 Sherbrooke East, Montreal, H1I 4M1, Canada; Dame, 1560 Sherbrooke East, Montreal, H1I 4M1, Canada;
Dr C Andersen, Odense University Hospital, DK 5000 Odense Dr C Andersen, Odense University Hospital, DK 5000 Odense
C, Denmark; Dr M Santini, Hospital Fillipo Neri, Via G MarC, Denmark; Dr M Santini, Hospital Fillipo Neri, Via G Mar-
tinotti 20, 00135 Rome, Italy; Dr M Romano, Ospitale S tinotti 20, 00135 Rome, Italy; Dr M Romano, Ospitale S
Corona, Viale Forlani 121, 20020 Garbagnate Mse, Italy; Prof Corona, Viale Forlani 121, 20020 Garbagnate Mse, Italy; Prof
Dr M Maritano, Battista e della citta di Torino, Corso Dr M Maritano, Battista e della citta di Torino, Corso
Bramente 90, 10126 Torino, Italy; Dr P Giampaolo, v Bembetti 300030, Robegano-Salzano (VE), Italy; Dr M J L DeJongste, Thoraxcenter, University Hospital Groningen, The Netherlands; Dr C P M Zomers, Lievenberg Hospital, Boerhaave plein 1, 4624 VT Bergen op Zoom, The Netherlands; Dr E Soyland, Baerum Hospital, Med Avd, N-1316 Sandvika, Norway; Dr M Garcia-Moll, Hospital de San Pablo, Avda San Ant Ma Claret 167, 08025 Barcelona, Spain; Dr L O Koskinen, University Hospital Umea, S-901 85 Umea, Sweden; Dr B Holtz, Smartmottagningen Lasarett, 27182 Ystad, Sweden; Dr C Mannheimer, Östra Hospital, S-41685 Göthenborg, Sweden.

1 Maseri A. Chronic stable angina. In: Maseri A, ed. Ischemic heart disease. New York: Churchill Livingstone, 1995:71$103 ; 477-505$

2 Jessurun GAJ, Meeder JG, DeJongste MJL. Defining the problem of intractable angina. Pain Rev 1997;4:89-99.

3 Schoebel FC, Frazier OH, Jessurun GAJ, et al. Refractory angina pectoris in end-stage coronary artery disease: evolvangina pectoris in end-stage coronary artery disease: evolv-

4 DeJongste MJL, Haaksma J, Hautvast RWH, et al. Effects of spinal cord stimulation on daily life with myocardial ischemia in patients with severe coronary artery disease. A ischemia in patients with severe coronary artery disease. A prospective

5 Mannheimer C, Augustinsson LE, Carlsson CA, et al. Epidural spinal electrical stimulation in severe angina pectoris. Br Heart $\mathcal{F}$ 1988;59:56-61.

6 Murphy DF, Giles KE. Dorsal collum stimulation for pain relief from intractable angina pectoris. Pain 1987;28:365-8. 7 González-Darder JM, Canela P, González-Martinez V. High cervical spinal cord stimulation for unstable angina pectoris. Stereotactic Funct Neurosurg 1991;56:20-7.

8 Sanderson JE, Ibrahim B, Waterhouse D, et al. Spinal electrical stimulation for intractable angina: long-term clinical outcome and safety. Eur Heart $\mathcal{f}$ 1994;15:810-14.

9 DeJongste MJL, Hautvast RWM, Hillege H, et al. Efficacy of spinal cord stimulation as an adjuvant therapy for intractable angina pectoris: a prospective randomized clinical ble angina pectoris: a prospective randon

10 DeJongste de MJL, Nagelkerke D, Hooyschuur CM, et al. Stimulation characteristics, complications, and efficacy of spinal cord stimulation systems in patients with refractory angina. A prospective feasibility study. PACE 1994;17: $1751-60$.

11 Andersen C, Hole P, Oxhoj H. Does pain relief with spinal cord stimulation for angina conceal myocardial infarction? Br Heart $\mathcal{F}$ 1994;71:419-21.

2 Mannheimer C, Eliasson T, Augustinsson L-E, et al. Electrical stimulation versus coronary artery bypass surgery in severe angina pectoris. The ESBY study. Circulation 1998;97:1157-63.

13 Landsheere $\mathrm{CH}$ de, Mannheimer C, Habets A, et al. Effect of spinal cord stimulation on regional myocardial perfusion assessed by positron emission tomography. Am 7 Cardiol 1992;69:1143-9.

14 Hautvast RWM, DeJongste MJL, Blanksma PK, et al. Spinal cord stimulation causes redistribution in myocardial perfusion during dipyridamole stress testing in patients perfusion during dipyridamole stress testing in patients
with refractory angina pectoris as assessed by $13 \mathrm{NH}_{3}$ positron emission tomography. Am f Cardiol 1996;77:462positrc

15 Chauhan A, Mullins PA, Thuraisingham SI, et al. Effect of transcutaneous electrical nerve stimulation on coronary blood flow. Circulation 1994;89:694-70.

16 Jessurun GAJ, TenVaarwerk IAM, DeJongste MJL, et al. Sequelae of spinal cord stimulation for refractory angina pectoris. Reliability and safety profile of long-term clinical application. Coron Artery Dis 1997;8:33-7.

17 Cameron AAC, Davis KB, Rogers WJ. Recurrence of angina after coronary artery bypass surgery: predictors and prognosis (CASS registry). F Am Coll Cardiol 1995;26:895-9.

$18 \mathrm{Gersh}$ BJ. Natural history of chronic coronary artery disease. In: Beller GA, Braunwald E, eds. Atlas of heart diseases, vol 5. Singapore: Imago Productions (Current Medicine series), 1995 .

19 Kirklin JW, Fish C, Bellen GA, et al. ACA/AHA Task Force Report. Guidelines and indications for coronary artery Report. Guidelines and indications for coronary arter
bypass graft surgery. $\mathcal{F}$ Am Coll Cardiol 1991;17:543-89.

20 Davis KB, Chaitman B, Ryan T, et al. Comparison of 15 -year survival for men and women after medical or surgi- 
cal treatment for coronary artery disease. A CASS registry study. F Am Coll Cardi 1995:25:1000-9.

21 Holmes DR, Davis K, Gersh BJ et al. Risk factor profiles of patients with sudden cardiac death and death from other cardiac causes: a report from the Coronary Artery Surgery Study (CASS). f Am Coll Cardiol 1989;13:524-30.

22 Cupples LA, D'Agostino RB. Survival following initia cardiovascular events: 36-year follow-up. Framingham
Heart Study, section 35. In: Kannel WB, Wolf PA, Garrison RJ, eds. The Framingham study: an epidemiological investigation cardiovascular disease. NiH publication No 88-2969. Bethesda: National Heart, Lung, and Blood Institute, 1988.
Lauer MS, Lytle B, Pashkow F, et al. Prediction of death and myocardial infarction by screening with exercise-thallium testing after coronary artery bypass grafting. Lancet 1998;351:615-22.

\section{IMAGES IN CARDIOLOGY}

\section{Mycotic aneurysm of the left pulmonary artery in a child with tetralogy of Fallot and Streptococcus viridans infective endocarditis}

A 2 year 8 month old girl with tetralogy of $\mathrm{Fal}-$ lot and a right modified Blalock-Taussig shunt was seen in January of 1998 with fever of a month's duration. The shunt had been created 11 months previously following a life threatening hypercyanotic spell. She had the physical signs of tetralogy as well as pneumonia. The shunt murmur was no longer audible.

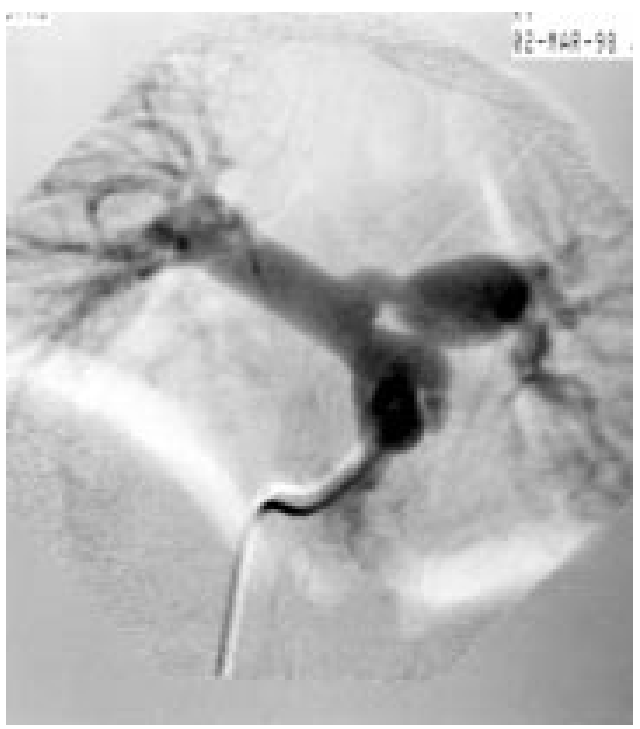

A Streptococcus viridans organism was cultured on two occasions from her blood. Echocardiography showed large masses consistent with vegetations proximal to the pulmonary valve and extending into the main pulmonary artery. Both branches of the pulmonary artery were dilated. After six weeks of antibiotic treatment she underwent cardiac catheterisation. This confirmed the clinical and echocardiographic diagnosis and showed the aneurysm. The figure is a digitally subtracted image obtained during angiography (left anterior oblique projection with cranial angulation). The tip of the catheter lies in the right ventricular outflow tract and contrast is seen to fill the main pulmonary artery and both branches. There is an aneurysm in the left pulmonary artery, which is $1.8 \mathrm{~cm}$ diameter at its widest point.

The patient underwent full repair on cardiopulmonary bypass. At surgery the mycotic aneurysm could not be seen as it was within the parenchyma of the left lung. The wall of the right pulmonary artery was indurated. There were no vegetations within the pulmonary arteries. The repair and subsequent postoperative course were uneventful. The patient was well 10 months after her initial illness.
JOHN LAWRENSON JOHN STIRLING JOHN HEWITSON 